\title{
EBSD-based Analysis of the Relation between Oxide Scale Microstructure and Pickling Characteristics of a Commercial Hot Rolled Strip
}

\author{
Gozde Karacali ${ }^{1}$, Kemal Davut ${ }^{2,3}$ \\ 1. Eregli Iron and Steel Works, Inc., Hot Rolled Products and Process R\&D Dept., Eregli, Zonguldak, \\ Turkey \\ 2. At1lim University, Metal Forming Center of Excellence, Incek, Ankara, Turkey \\ 3. Atılım University, Department of Metallurgical and Materials Engineering, Incek, Ankara, Turkey
}

Oxidation is a general problem for almost all of the metals at raised process temperatures. For steels, especially during hot rolling, an oxide scale forms and later effects the surface quality. The surface quality, and hence, the commercial value of final products depend on the oxide scale properties and capability of removing them by steel manufacturer [1]. The relation between initial microstructure of the scale and its removal by acid pickling, therefore has a great importance.

The oxide scales display different properties, characteristics and morphologies in hot rolling process on a hot strip mill, which involve a reheating furnace, descalers, a roughing mill, finishing mills, a run-out table and down coilers respectively [2]. These iron oxides can be classified the primary, the secondary and the tertiary scales with regard to formation region. During the hot rolling process, the primary scales formed on slabs surface in the reheating furnace and then they are removed by desclares. After removing the primary scales, the secondary scales growth quickly on slab surface in temperatures between $900-1200{ }^{\circ} \mathrm{C}$. Before the finishing mill, next descaler performs to remove them. Furthermore, the tertiary scale develops on surface during the finish milling and cooling processes [3].

The oxide scales are usually composed of three iron oxide phases; namely, hematite $\left(\mathrm{Fe}_{2} \mathrm{O}_{3}\right)$, magnetite $\left(\mathrm{Fe}_{3} \mathrm{O}_{4}\right)$ and wustite $(\mathrm{FeO})$ layers and they are usually located on the top, in the middle, and at the bottom of the scale layer, respectively. The thicknesses of these three layers can vary by chemical compositions, oxidation conditions [4] and surface finish [5].

The characterization of the oxide scale developed on hot-rolled strip surface is significant to following processing such as pickling and cold rolling. In this study, the oxide scales developed on commercial hot-rolled strips were characterized by a variety of techniques and then the complex relationship between oxide scale properties (phase, grain boundary character and grain size) and the pickling process were investigated. Previous studies [6], investigated this relationship as well, however those studies concentrate only on in-house laboratory scale products.

In this study, the hot-rolled-strips were taken from the mills of a commercial-integrated line. The pickling process was realized in samples cut from the strips, in a solution of 30 parts $\mathrm{HCl}, 70$ parts water. The samples dipped into this solution for 0.5 - 30 minutes. Afterwards, the microstructure of the pickled samples were compared to the initial non-pickled condition.

The electron back-scatter diffraction (EBSD) technique was used to characterize the different layers and the texture as well as orientation relations of the scale layer of the samples. Since the crystal structure of those layers are different, EBSD technique can successfully identify them. Moreover, the oxide scale layers were characterized by Nikon Eclipse MA200 optical light microscope (OLM), Jeol JSM 7001F Schottky field emission gun (FEG) scanning electron microscope (SEM), energydispersive X-ray spectroscopy (EDS). EBSD and EDS analysis were performed on the mentioned FEG-SEM equipped with Oxford INCA and CHANNEL 5 software packages. 
The results indicate that, the scale layer on the present hot-rolled strip is composed of mainly "magnetite". Moreover, the parts of this scale having larger grain size and higher energy grain boundaries are more easily pickled.

\section{References:}

[1]. R. L. Higginson, B. Roebuck, E. J. Palmiere, Scripta Materialia, 47 (2002), p. 337.

[2]. W. L. Roberts, "Hot Rolling of Steel”, Marcel Dekker Inc., New York (1983), p.621

[3]. Yu, X. et al, Adv. Mater. Res., 415-417 (N/A), (2012) p. 853.

[4]. R. Y. Chen and W. Y. D. Yuen, Oxid. Met., 59 (2003), p. 433.

[5]. S. Weihua, et al, J. Mater. Process. Technol. 140 (2003), p. 76.

[6]. M. Zhang, G. Shao, Mat. Sci. and Eng. A 452-453 (2007), p. 189.

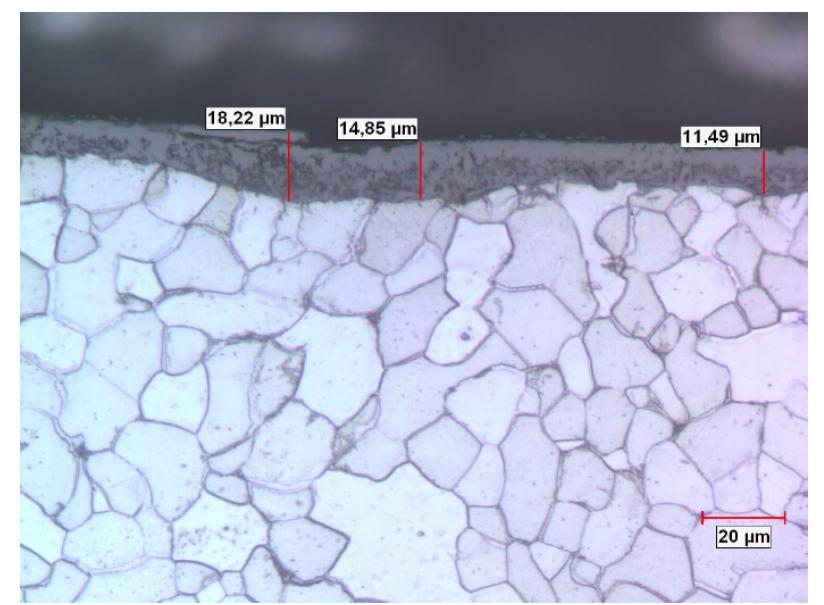

Figure 1. Micrograph showing the oxide scale and its thickness formed on the commercially hot-rolled strip.

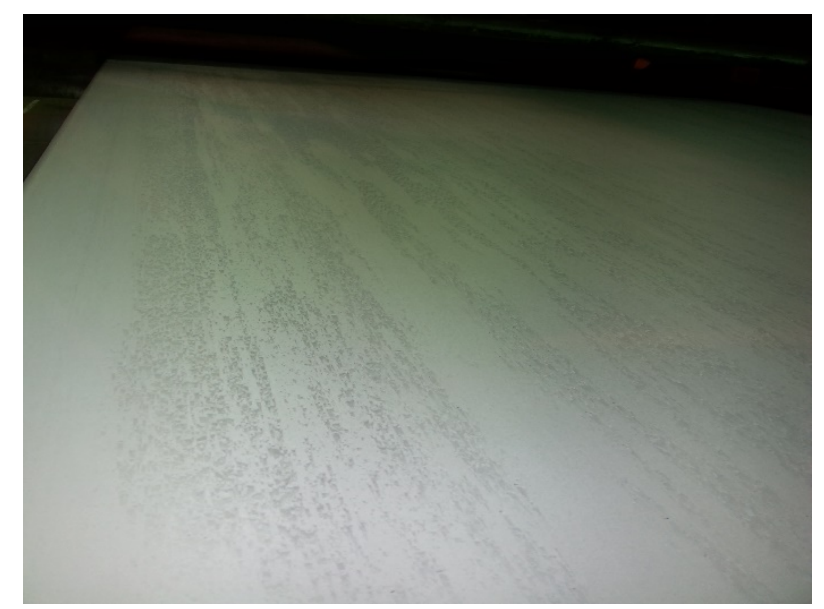

Figure 2. The surface of the hot rolled strip after the pickling process showing partially removed oxide scale. 